\title{
POLÍTICAS SOCIALES, PARTICIPACIÓN \\ Y DIVERSIDAD CULTURAL: \\ EL CASO DE LOS MIGRANTES EN ARGENTINA
}

\section{Graciela Tonon ${ }^{1}$ \& Lía Rodríguez de la Vega ${ }^{2}$}

\section{Introducción}

El artículo presenta la situación de los migrantes en la Argentina a partir de un recorrido histórico de las distintas políticas públicas para el área. Asimismo expresa la razón por la cual es éste un problema relevante para el Trabajo Social, rescatando la idea de la necesidad de contar con una política de reconocimiento para la diversidad.

\section{La participación ciudadana y el reconocimiento de la diversidad}

En la actualidad, la mayor parte de las personas no encuentran su principal fuente de felicidad en la política sino que en la vida familiar, el trabajo, la religión o el ocio. La actividad política es vista como ocasional y cuando es necesaria, en razón de proteger los derechos particulares, es decir lograr que el gobierno respete y proteja la libertad de los ciudadanos. Kymlicka y Norman (1994) analizan la cuestión de la indiferencia moderna hacia la participación política, más que argumentando que la vida política actual se ha empobrecido con relación a la de la antigua Grecia, desde otro punto de vista:

...es más verosímil ver nuestro apego a la vida privada como el resultado no de un empobrecimiento de la vida pública, sino del enriquecimiento de la vida privada. Si ya no buscamos gratificaciones en la política es porque nuestra vida social y personal es mucho más rica que la de los griegos. Muchas son las razones de este cambio histórico: la valoración del amor romántico y de la familia nuclear (con su énfasis en la intimidad y privacidad), la creciente prosperidad (y el consiguiente enriquecimiento de las formas de ocio y de consumo) la afirmación cristiana de la dignidad del trabajo (que los griegos

\footnotetext{
Profesora, Universidad Nacional de la Matanza, Argentina.

2 Investigadora, Universidad del Salvador, Argentina.
} 
despreciaban) y la creciente aprensión hacia la guerra (que era positivamente valorada por los griegos)... (Kymlicka \& Norman, 1994, p. 280).

Para los ciudadanos actuales, la política se ha separado de los asuntos de la vida cotidiana, perdiendo su carácter comunitario, deshumanizándose. Y esta política que se identifica mayoritariamente con el poder, es rechazada por el ciudadano, si bien éste no rechazaría una política relacionada con lo comunitario y con el establecimiento de lazos sociales de solidaridad. Es necesario entonces, que «lo público» no aparezca anexado al gobierno o a los partidos políticos en forma excluyente y que las organizaciones sociales no sean apolíticas y desligadas de la "cosa pública". Lo que se necesita es, revalorizar la relación entre el Estado y los ciudadanos y redefinir el espacio público como un espacio compartido del "nosotros".

Es en las "redes asociativas" de la sociedad civil, es decir, en las organizaciones voluntarias de la sociedad civil: iglesias, asociaciones étnicas, familias, asociaciones de vecinos, grupos de protección, asociaciones de beneficencia, etc., donde las personas aprenden el compromiso mutuo. Sin embargo, las personas se reúnen en este tipo de asociaciones para poner en práctica ciertos valores y disfrutar de ciertos bienes y no para lograr la promoción de la ciudadanía, por lo que podría parecer un tanto ambicioso hacer recaer en estas asociaciones la enseñanza de las condiciones de la ciudadanía democrática.

Ahora bien, las personas se identifican en general por sus relaciones de grupo y es así que se definen por lealtades morales y universales: por ejemplo el ser católico, el ser demócrata, etc. Pero también se agrupan basándose en su pertenencia histórica y por ende en tanto a una cultura que establece qué cosas tienen importancia y cuáles no la tienen. Contemporáneamente, la mayoría de las personas tienen identidades complejas producto de la conjunción entre lealtades universales y las formas de pertenencias históricas. La pertenencia al grupo proporciona una parte importante de la identidad de las personas y si existen varias personas que se identifican con un grupo, éste adquiere una identidad colectiva a la que subyace una acción común en la historia. 
En este momento, recordemos que la primera lucha en el logro de la ciudadanía radicó en la intención de evitar que hubiera ciudadanos de primera clase y ciudadanos de segunda clase. Y más allá de que discutamos la existencia o no de la igualdad, por ejemplo, desde las posibilidades económicas, nadie puede discutir que el principio de ciudadanía igualitaria llegó a ser universalmente aceptado. El segundo cambio se produjo cuando al desarrollarse el concepto moderno de identidad se generó la política de la diferencia, la cual también tiene una base universalista. En este sentido cada cual debe ser reconocido por su identidad única, y esto quiere decir que la intención es reconocer el igual derecho a ser reconocido en tanto ser distinto. Es un reconocimiento de la especificidad.

Pero estas dos políticas, que comparten el concepto básico de la igualdad de respeto, entraron en coalición. Para una, el principio de respeto igualitario hace que no se tengan en cuenta las diferencias y para la otra, en cambio, hay que fomentar la particularidad. La segunda critica a la primera diciendo que ésta, niega la identidad a las personas al ponerlas dentro de un molde, que por supuesto ha sido producto de la cultura dominante. Al respecto Taylor (1995, p. 20) dice: "La exigencia del reconocimiento, fomentada por el ideal de la dignidad humana, apunta al menos en dos direcciones, tanto a la protección de los derechos básicos de los individuos cuales seres humanos, como al reconocimiento de las necesidades particulares de los individuos cuales miembros de grupos culturales específicos".

La pertenencia cultural tiene un alto perfil social para las personas ya que afecta la forma en que los demás las perciben y les responden, lo que a su vez modela su identidad. Es así que la identidad nacional resulta un foco de identificación primario ya que se basa en la pertenencia y no en la realización, esto quiere decir que, está menos amenazada ya que no depende de la realización individual de la persona. La identidad cultural proporciona un anclaje para la autoidentificación y la seguridad de una pertenencia estable sin mayores esfuerzos. Pero, esto a su vez significa que el respeto a sí mismo, está vinculado con la estima que merece su grupo nacional. Si un grupo no goza de respeto general, la dignidad y el respeto de sus miembros están amenazados. En tal sentido, Tamir (1993) señala que: 
la pertenencia cultural añade un significado adicional a nuestras acciones, que se convierten no sólo en actos de realización individual, sino que también en parte de un continuo esfuerzo creativo mediante el cual se crea y se recrea la cultura. Si las instituciones están modeladas por una cultura comprensible y significativa para las personas, ello permite un cierto grado de transparencia que facilita su participación en los asuntos públicos, lo cual fomenta el sentimiento de pertenencia y las relaciones de reconocimiento y responsabilidad mutua (p. 8586).

\section{Los derechos multiculturales}

El fenómeno de las migraciones en el momento histórico actual ha llevado, necesariamente a los Estados a plantearse que sus fronteras son en realidad porosas y que la homogeneidad cultural que pensaban poseer, se ha convertido en una heterogeneidad pluricultural. Tomaremos la idea de que un Estado es multicultural si sus miembros pertenecen a naciones diferentes, (Estado multinacional), o si éstos han emigrado de distintas naciones, (Estado poliétnico), siempre que ello suponga un aspecto importante de la identidad personal y la vida política. Ahora bien, es necesario que consideremos que Estado y etnicidad son dos términos, hasta el momento, divorciados. Y si bien el Estado debe proteger a los diferentes grupos contra la discriminación; en la práctica los organismos públicos no conceden identidades o discapacidades legales en relación a la pertenencia cultural o a la identidad étnica. Y es esta separación entre Estado y etnicidad la que imposibilita el reconocimiento legal o gubernamental de los citados grupos y por ende el uso de criterios, a tal fin, en la distribución de derechos, responsabilidades y recursos. Glazer (1983) señala que el Estado se comporta con desatención benigna, ya que no se opone a la libertad de las personas para que expresen su filiación cultural específica pero tampoco incentiva la citada expresión. Así los distintos grupos étnicos cuentan en un Estado democrático con la protección contra la discriminación y los prejuicios, teniendo libertad para mantener los aspectos de su herencia cultural que deseen, siempre que los mismos no lesionen los derechos de los demás. Los derechos poliétnicos se definen, entonces, como aquellos que "...tienen como 
objetivo ayudar a los grupos étnicos y a las minorías religiosas a que expresen su particularidad y su orgullo cultural sin que ello obstaculice su éxito en las instituciones económicas y políticas de la sociedad dominante" (Kymlicka, 1996, p. 53).

En el caso de los derechos poliétnicos es necesario que consideremos que el contexto de elección de los inmigrantes a diferencia del de las minorías nacionales implica un igual acceso a la cultura imperante, ya que se supone que al haberse desarraigado de su antigua cultura se convertirán en miembros de las sociedades nacionales ya existentes en el país que habitan en la actualidad, por lo cual fomentar los rasgos positivos de la pertenencia cultural, redunda en propiciar la integración de los mismos. Es así que se intenta reforzarles los derechos comunes de ciudadanía más que concederles derechos diferenciados en tanto grupo específico. Al respecto Kymlicka (1996) expresa que, con relación a los grupos de inmigrantes:

Propiciar la integración requiere, en primer lugar, contundentes esfuerzos para combatir los prejuicios y la discriminación. Esto no sólo implica reforzar las leyes antidiscriminatorias, sino también cambiar la imagen que se da de los inmigrantes en los libros de texto, en los documentos del gobierno y en los medios de comunicación. Además, propiciar la integración puede exigir alguna modificación de las instituciones de la cultura dominante en la forma de los derechos poli étnicos específicos en función del grupo..... Los inmigrantes pueden insistir legítimamente en mantener parte de su herencia y las instituciones dominantes deberían adaptarse para dar cabida a estas diferencias (Kymlicka, 1996, p. 137).

Es necesario señalar que los derechos multiculturales tienden a la integración del grupo a la sociedad global y no a la independencia del mismo. Nos referimos a grupos que de alguna manera están o se sienten excluidos y luchan por ser incluidos en la sociedad global, por lo cual el reconocimiento de su diferencia es un camino para facilitar su proceso de inclusión. Son grupos que quieren obtener un mayor reconocimiento en la sociedad en la cual viven y lograr modificaciones en las instituciones y leyes de dicha sociedad con el objetivo de que la misma 
se torne permeable a las diferencias culturales. La mayoría de las reivindicaciones de estos derechos se relacionan con lo que se denominan protecciones externas frente a la comunidad principal. Entendiéndose por protecciones externas aquellas que corresponden a las relaciones intergrupales y que tratan de proteger la existencia e identidad específica de un grupo, limitando el impacto, sobre él, de las decisiones de la sociedad en la cual se encuentra englobado.

Finalmente, podemos decir que, el reconocimiento universal de la ciudadanía se lograría con la institucionalización de valores comunes que supongan la igualdad de oportunidades y el derecho a tener subjetividades propias. De esta manera, al asumirse colectivamente los valores ciudadanos universales se podrían expandir las identidades particulares, se aceptaría al otro y se asumiría el multiculturalismo abierto. Y si nuestro objetivo es la integración, el logro de la misma requiere, en primera instancia, terminar con los prejuicios y la discriminación, cuestiones ambas que implican el predominio de poder de unos sobre otros. Porque la integración en su carácter de proceso multidimensional, es en sí mismo multicultural y la consideración del multiculturalismo implica la política del reconocimiento, contraria a la discriminación y en favor de la diferencia como posibilidad de lograr la convivencia en comunidad.

\section{El problema social de las migraciones}

\section{La migración como área de intervención del Trabajo Social}

Las migraciones, como sabemos, implican el movimiento de los migrantes desde el territorio del cual son originarios hacia aquel de residencia, con una permanencia más o menos duradera. Cuando las migraciones son internacionales, generan en los migrantes consecuencias en sus derechos ya que modifican su relación con el país de origen y con el de residencia, trascendiendo además el ámbito de esos Estados, pasando a ser objeto también de organizaciones internacionales. Los migrantes se convierten así en destinatarios de normas jurídicas de diversa naturaleza. 
Nuestra primera reflexión se centra en relación a referirnos a las migraciones como problema social y como campo de interés para el Trabajo Social. Trabajo Social como cualquier profesión, inscripta en la división social y técnica del trabajo, depende de su utilidad social. Esto es que sea capaz de responder a las necesidades sociales, que son la fuente de su demanda. La práctica profesional del trabajador/a social es considerada como una forma de trabajo cualificado que se desarrolla en un espacio con características específicas, que resulta de un devenir histórico y que se caracteriza por la existencia de una multiplicidad y simultaneidad de dimensiones que hacen que sus resultados no sean siempre previsibles. Estas dimensiones a las cuales nos referimos no resultan solamente técnicas, sino que también son éticas y políticas, haciéndose necesaria, entonces la existencia de un profesional formado en competencias contextuales. ${ }^{2}$

Si bien la tendencia histórica del trabajador social como operador de políticas sociales se mantiene, se han modificado los escenarios en los cuales actúa, ya que las nuevas tendencias en el área de las políticas sociales, señala la posible existencia de áreas de intervención potenciales (García Salord, 1991). La problemática de la migración compone claramente una de esas áreas a las cuales nos referimos y Trabajo Social cuenta con la autoridad científica y profesional necesaria, es decir, con la capacidad técnica y la competencia científica socialmente reconocida, para hacerlo.

\section{La definición de migrante}

El primer tema que consideraremos es el de la delimitación del concepto jurídico del migrante y las categorías de migrantes. La doctrina y los instrumentos jurídicos no presentan una definición constante de migrante; lo común es que cada texto establezca sus propias definiciones, atendiendo a los objetivos para los que es redactado. Es por esto que se busca el recorte del concepto por el método de la exclusión, de su ámbito, de las categorías de personas que, en función del objetivo de sus respectivas salidas de su país de origen, no son considerados migrantes por el lenguaje jurídico. Ellos son: los que

\footnotetext{
${ }^{2}$ Para ampliar el tema ver Tonon, G. Trabajo social: profesión y disciplina. Revista Saberes y Haceres. Año 3. No. 3, Universidad Autónoma del Sur, Chile.
} 
salen de su país por turismo, los que salen por motivos de salud, los que salen de su país de origen por viajes de negocios en el ámbito internacional, los que salen de su país por motivo de servicio público del Estado que los envía.

Atendiendo a lo mencionado, consideramos migrantes a aquellos que no estando incluidos en los puntos ya mencionados, salen de su país de origen por motivos de persecución, para ejercer en otro territorio cualquier actividad, por cuenta propia o en relación de dependencia, ganando dinero con ello o a título gratuito, o para permanecer en otro territorio por un tiempo de duración prolongada, generalmente con transferencia de residencia habitual.

\section{Las categorías de migrantes}

Considerando la naturaleza jurídica de los territorios entre los cuales ocurre la migración, los migrantes pueden ser internos o internacionales, en tanto traspongan o no las fronteras de su Estado de origen. En función de los motivos para salir de su Estado de origen y de la situación en que se encuentran en el país de residencia, los migrantes pueden ser: migrantes que realizaron pedido de asilo, refugiados, migrantes no activos (migraron por motivos de estudio, formación profesional, etc., cualquier motivo que no involucre el ejercicio de una actividad profesional), inversores activos (los que ejercen una actividad profesional remunerada), entre los que están: los funcionarios de organizaciones internacionales, cuyo status jurídico-laboral está regido por convenciones multilaterales específicas, los cooperantes (personal técnico que un estado envía a otro), que pueden estar regidos por normativa del estado de origen, del estado receptor o por convenciones bilaterales entre ambos y los trabajadores migrantes (Rocha-Trindade, 1995).

\section{Los trabajadores migrantes y sus derechos}

El concepto trabajador migrante, en sentido más amplio está dado por la Convención Internacional relativa a la Protección de Derechos de todos los Trabajadores Migrantes y miembros de su familia, aprobada por la Asamblea General de la Organización de las Naciones Unidas, en diciembre de 1990. En sus términos, "trabajadores 
migrantes son las personas que van a ejercer, ejercen o ejercerán una actividad remunerada en un Estado del que no son nacionales".

Frecuentemente se consideran diversas categorías de trabajadores migrantes, a saber:

1) considerando el modo de ejercicio de la actividad profesional en el extranjero, por cuenta propia o en dependencia.

2) Atendiendo a la duración de la estadía del trabajador migrante en el país de empleo; sean permanentes o temporarios.

3) Considerando el status jurídico en el país de residencia.

De todas estas consideraciones depende que la situación del trabajador migrante sea regular o irregular.

Las convenciones multilaterales que se relacionan más directamente con las migraciones y los derechos de los migrantes son las de la OIT, número 97 (1949) y número 143 (1975) respectivamente sobre Trabajadores Migrantes y sobre Migraciones en Condiciones Abusivas y Promoción de la Igualdad de Oportunidades y de Tratamiento de los Trabajadores Migrantes.

Fue la OIT la primera en señalar la necesidad de vincular los Estados a algunos de los principios básicos, para evitar la precariedad de situación de quienes pretendían trabajar en el extranjero; también la OIT, en 1975, incluyó en el derecho internacional la idea de que los Estados de residencia (o acogida del o los migrantes) debían elaborar políticas globales, que buscasen realizar y garantizar la igualdad de oportunidades de los trabajadores migrantes y sus familias en situación regular, en lo atinente a su empleo, actividades profesionales y seguridad social, los derechos sindicales, culturales y las libertades individuales o colectivas.

Otras convenciones multilaterales son importantes para los migrantes y sus familias, aunque no sean expresos y exclusivos destinatarios de las normas de estos instrumentos jurídicos. En cuanto a Derechos Económicos, Sociales y Culturales y Condiciones de Vida y de Empleo: Las Convenciones de la OIT $n^{\circ} 87$ sobre Derecho Sindical, la $n^{\circ} 96$ sobre Agencias de Colocación, la $n^{\circ} 111$ sobre Discriminación en 
materia de Empleo y Profesión y la n 142 sobre Formación Profesional. En cuanto al Derecho de Familia y al Derecho de Menores: La Convención de la ONU y las de la Conferencia de La Haya de Derecho Internacional Privado, sobre derecho de alimentos, Las Convenciones de la Conferencia de La Haya, sobre protección de menores y guarda de hijos (Rocha-Trindade, 1995).

Los derechos humanos fundamentales y las organizaciones internacionales

El núcleo de los derechos humanos está garantizado por Convenciones Internacionales de aplicación universal. Las Convenciones más significativas en este ámbito son las de las Naciones Unidas: la Declaración Universal de los Derechos Humanos (1948), el Pacto Internacional sobre Derechos Civiles y Políticos (1966) y el Pacto Internacional sobre los Derechos Económicos, Sociales y Culturales (1966). El instrumento regional, en América, sobre esta materia, cuya aplicación es de ámbito universal es la Convención Americana relativa a los Derechos Humanos (1969), adoptada por los Estados miembros de la Organización de Estados Americanos.

En la lucha contra la discriminación, se han dado las siguientes convenciones, todas celebradas en el ámbito de la ONU:

* La Convención Internacional sobre la eliminación de todas las formas de discriminación racial (en vigor desde 1969),

* La Convención relativa a la discriminación en el empleo y la profesión (en vigor desde 1960),

* La Convención relativa a la lucha contra la discriminación en la esfera de la enseñanza (en vigor desde 1962),

* La Convención sobre la eliminación de todas las formas de discriminación en relación a las mujeres (en vigor desde 1981).

Existen otros textos jurídicos que abarcan la situación de los apátridas, asilados y refugiados, como las convenciones dadas en el ámbito de Naciones Unidas (la Convención sobre la reducción 
de casos de apátridas, en vigor desde 1975, la Convención relativa al estatuto de los apátridas, en vigor desde 1960, la Declaración Universal de los Derechos Humanos, que reconoce a toda persona, sometida a persecución, pedir asilo y beneficiarse con el asilo en otros países, la Convención de las Naciones Unidas relativa al status de los refugiados (o Convención de Ginebra), en vigor desde 1954 y Protocolo Adicional (o Protocolo de Nueva York), en vigor desde 1967). La protección de los refugiados está asegurada también por el Alto Comisionado de las Naciones Unidas para los Refugiados.

Las Organizaciones Internacionales que intervienen de manera más específica en el área de migraciones y los derechos de los migrantes son: la organización de las Naciones Unidas (ONU), la Organización Internacional del Trabajo (OIT), la Organización Internacional de las Migraciones (OIM), la Organización para la Cooperación Económica y el Desarrollo (OCDE), la Conferencia de la Haya de Derecho Internacional Privado y la Comisión Internacional de Estado Civil. La naturaleza de las intervenciones de cada uno de estas organizaciones es diversa, según sus fines, pero, cabe decir que, de una manera u otra, han contribuido a mantener en la agenda política internacional las migraciones y la situación de los migrantes, buscando la profundización de sus derechos individuales en el Estado, sea este el de origen o el de residencia (Rocha-Trindade, 1995).

\section{Las políticas de migración en Argentina}

Focalizando el estudio en la situación de los migrantes en Argentina, podemos decir que la primera Constitución Nacional que data de 1853, posteriormente modificada, planteaba una controversia en torno a la sinonimia o distinción atribuidos a los términos nacionalidad y ciudadanía. La ciudadanía implica una idea de Estado, generalmente soberano, aludiendo así a un concepto político mientras que la nacionalidad implica la existencia de una sociedad civil con los caracteres de una Nación, sin condicionalidad política. Así, en este texto, ambos vocablos se usaban indistintamente en los artículos 8 , $20,21,40,47,67$ inciso $11,74,76$ y 108, o bien se usaba "ciudadano" como sinónimo de "habitante", de "nacional" o como equivalente a "nacional" o "extranjero" con el goce de derechos políticos. El artículo 
8, establecía que "los ciudadanos de cada provincia gozan de todos los derechos, privilegios e inmunidades inherentes al título de ciudadano en las demás". El goce de derechos civiles es común a argentinos y extranjeros, es decir a los habitantes (Acosta Rivellini, 1985). Asimismo, en su artículo 20, la Constitución establecía que los extranjeros obtienen nacionalización residiendo dos años continuos en la Confederación, aunque la autoridad puede acortar ese término a favor del que lo solicite, alegando y probando servicios a la República. No establece una edad determinada para peticionar la naturalización.

En 1862, una nueva norma autoriza al Poder Ejecutivo a celebrar contratos sobre inmigración extranjera otorgando tierras. Tal donación obligaba a los colonos a poblar dichas tierras durante dos años, plazo en el cual la escritura de la propiedad les sería otorgada (Ley 25) (Novick, 1992).

En 1865, la Ley 346, distinguió la ciudadanía por "nacimiento", "por opción" y “por naturalización". La referida al nacimiento hacía mención a los nacidos en territorio argentino o ámbitos bajo su soberanía, la segunda, "por opción", referida a los hijos de argentinos nacidos en el extranjero que optaren por la "ciudadanía" de origen y la tercera, "por naturalización", para los extranjeros que reunieran determinadas condiciones: antigüedad de residencia, servicios prestados a la república, etc. Los derechos políticos se adquirían a los 18 años, tal como sostenía la Constitución. Esta Ley estableció los 18 años de edad para el extranjero que deseara naturalizarse y dos años de residencia continuada en la república, plazo que podría reducirse si a criterio del tribunal interviniente, quien peticionara acreditase servicios a la Nación. No estableció, como condición para el peticionante, antecedentes morales o de consubstanciación con los principios fundamentales de las instituciones políticas del país (Acosta Rivellini, 1985).

La llamada Ley Avellaneda, ley 817, de 1876, es la que legislará ambos fenómenos: el de la inmigración y la colonización. En ella se definió por primera vez, a nivel legislativo, qué es un inmigrante "todo extranjero, jornalero, artesano, industrial, agricultor o profesor que siendo menor de sesenta años y acreditando moralidad y aptitudes 
llegase a nuestro país para establecerse en él" (Novick 1, 1992). Asimismo, se creó el Departamento General de Inmigración, que funcionó bajo la órbita del Ministerio del Interior (Novick 1, 1992).

Sin embargo, hacia 1902, la Ley 4.144, reguló la residencia de extranjeros e introdujo una nueva imagen de ellos: los extranjeros condenados o perseguidos por crímenes o delitos comunes, cuya conducta puede comprometer la seguridad de nuestro país o perturbar el orden público. En 1907, se sancionó una norma referida al trabajo de mujeres y de menores. Se estipulaba que no podían trabajar más de 8 horas diarias, se prohibía que trabajaran en industrias peligrosas o insalubres, y los lugares de trabajo debían contar con asientos para las obreras siempre que el trabajo así lo permitiese. Se sancionaba penalmente el hacer trabajar a menores de 16 años en trabajos peligrosos, de fuerza o dislocación. Se establecía el derecho de amamantamiento en el trabajo y de reposo post- parto. Se prohibía el trabajo nocturno, salvo el de las enfermeras y el personal doméstico. Se prohibía el trabajo de mujeres en espectáculos públicos, aún cuando fuesen mayores de 18 años (Novick 2, 1992).

En 1932, la legislación se refiere al inmigrante "indeseable", tratante de blancas o delincuente, ampliándose las facultades de la Dirección de Inmigración para la vigilancia de la entrada de extranjeros. Considerando la grave crisis económica, un decreto del mismo año, dice que, para defender a los trabajadores ya radicados en nuestro país, es necesario impedir la entrada de inmigrantes que no tengan "de antemano asegurada una ocupación remunerativa o la subsistencia". De esta manera, desde el $1^{\circ}$ de enero de 1933 , los cónsules, no visarían documentos de aquellos inmigrantes que no tuviesen asegurado trabajo en el país y el ingreso de parientes se habría de permitir solamente cuando el que los llamase prometiera tomarlos a su cargo. Posteriormente y en 1938 se menciona, por primera vez, la necesidad de llevar un registro oficial y permanente sobre la entrada y salida de extranjeros para poder formular una política inmigratoria adecuada.

En 1948, se da la Declaración Internacional de Derechos del Hombre, que establece que a nadie se le ha de privar arbitrariamente del derecho de cambiar de nacionalidad. En 1949, se dicta el primer decreto de 
amnistía por el que se considera como radicados de hecho a todos los extranjeros que acreditasen residencia y arraigo en el país anterior al 8 de julio de 1949 (Novick 2, 1992).

La Ley 14.354, de 1954, estableció que la ciudadanía es un atributo de la nacionalidad que implica el ejercicio de los derechos políticos consagrados por la constitución y la ley positiva y dejó en claro que los argentinos nativos entraban en ejercicio de la ciudadanía a los 18 años y los naturalizados (con más de18 años) a los 5 años de adquirida la nacionalidad. Introduce también el sistema de naturalización automática para los extranjeros con 5 años de residencia continua (Acosta Rivellini, 1985).

En 1956, se dicta una norma que equipara los salarios de mano de obra femenina y masculina, por trabajo de igual valor (Decreto 2739/56) (Novick 2, 1992). Hacia 1963, bajo el gobierno militar del Dr. Guido, se elaboró una norma que reglamenta la admisión, permanencia y expulsión de extranjeros, siendo la Dirección Nacional de Migraciones, la institución encargada de conceder radicaciones definitivas y otorgar permisos de ingreso al país. En 1965, bajo la presidencia de Illia, se elabora un decreto que clasifica a los extranjeros admitidos en el país en dos categorías: los con residencia permanente y los con residencia no permanente. Los primeros podían ser: inmigrantes, refugiados, ex residentes o familiares de argentinos. Los segundos reconocían las siguientes subcategorías: temporarios, turistas, trabajadores de temporada, pasajeros en tránsito, asilados políticos y de tránsito vecinal fronterizo. Durante el gobierno militar de Onganía, se implanta un intenso control de entrada de extranjeros, buscando "impedir la inmigración clandestina". La norma prohíbe a todo extranjero ilegal desarrollar tareas o actividades remuneradas y, las reparticiones públicas, empleadores, hoteleros, etc., deberán exigir constancia de residencia legal, debiendo denunciar las situaciones irregulares en un plazo máximo de 24 horas. Las disposiciones transitorias establecen que todo empleador que tuviese personal extranjero deberá exigirle su documentación; y si no la tuviese lo denunciará ante la Dirección Nacional de Migraciones para que regularice su situación y si en el plazo de 90 días no lo hiciera, procederá a su inmediato despido (Ley 17.294). 
En 1974, se sanciona la Ley de Contrato de Trabajo, que regula integralmente las relaciones laborales, excepto las de los empleados públicos, provinciales, municipales y servicio doméstico que se rigen por leyes especiales (Novick 1, 1992). En 1977, bajo el llamado "Proceso de Reorganización Nacional", se dicta el Decreto 3.938/77 que establece que debe incrementarse el flujo inmigratorio sensiblemente, seleccionado a aquellos que aseguren condiciones sanitarias y culturales que permitan su integración en nuestra sociedad y se prevé la creación de fuentes de trabajo para incorporar la mano de obra inmigrante.

En 1978, la Ley 21.795, determina que los argentinos nativos son: a) los nacidos en el territorio argentino, sus aguas jurisdiccionales, su espacio aéreo, con excepción de los hijos de extranjeros, cuyo padre o madre se encontrase en el país como agentes del servicio exterior o en función oficial de un estado extranjero o en representación de organismos interestatales reconocidos por la República, siempre que conforme a la legislación del Estado, cuya nacionalidad posean los padres, no les correspondiere la nacionalidad argentina, b) los nacidos en las legaciones, sedes de las representaciones diplomáticas, aeronaves y buques de guerra argentinos, c) los nacidos en alta mar o en zona internacional o en sus respectivos espacios aéreos, bajo pabellón argentino, d) los hijos de padre o madre argentinos, que nacieren en territorio extranjero, siempre que el padre o la madre se encontraren en el exterior prestando servicios oficiales para los gobiernos nacional, provinciales o municipales. En lo referido a los "argentinos por opción", sostiene que serán argentinos nativos, los nacidos en el extranjero, de padre o madre argentinos nativos, a petición de quien ejerza la patria potestad, solicitada al tribunal federal con jurisdicción en el domicilio del peticionante dentro de los cinco años de la fecha del nacimiento. También podrá ser formalizada por el interesado, dentro de los tres años posteriores al cumplimiento de los 18 años de edad, si acreditase saber leer, escribir y expresarse, inteligiblemente en el idioma nacional. Para ello, se requerirá que el peticionante tenga establecido su domicilio en el país durante 2 años, ininterrumpidamente al momento de formalizar la solicitud. Con respecto a la "naturalización", determina que el extranjero debe tener una buena conducta, conocer de modo elemental los principios constitucionales, no ser sordomudos que no pueden darse a entender por escrito, dementes o personas disminuidas 
mentalmente, no haber sido condenados en Argentina por delitos dolosos a una pena privativa de la libertad mayor de 3 años, aunque la condena haya sido cumplida o mediante indulto o amnistía, no haber sido condenados en el extranjero por delitos dolosos previstos en la legislación penal argentina y reprimidos por ésta con pena privativa de libertad mayor de 3 años, aunque la condena haya sido cumplida o mediante indulto o amnistía, no integrar ni haber integrado, en el país o en el extranjero, grupos o entidades que por su doctrina o acción aboguen, hagan pública exteriorización o lleven a la práctica, el empleo ilegal de la fuerza o la negación de los principios, derechos y garantías establecidos por la Constitución Nacional y, en general, que no realicen ni hayan realizado actividades de tal naturaleza en el país o en el extranjero por delitos previstos en la legislación penal argentina, hasta que no sean separados de la causa; no ser, no haber sido nacionales de un país que se encuentre en guerra contra la Nación Argentina. Otras condiciones son el saber leer, escribir y expresarse inteligiblemente en el idioma nacional, tener medios honestos de vida. El otorgamiento de la correspondiente carta de naturalización implica la asimilación al argentino nativo. Además, transcurridos los plazos de la ley, puede ser electo diputado, senador, ministro del Poder Ejecutivo y de la Corte Suprema de Justicia. Cabe aclarar, además, que son los jueces federales, estableciendo los recaudos y fijado el procedimiento judicial, la autoridad competente para el otorgamiento de la carta de nacionalidad (Acosta Rivellini, 1985).

Finalmente, en 1981, el gobierno del general Videla elabora una norma que sustituye a toda la legislación vigente sobre migraciones (deroga la Ley Avellaneda, el decreto-Ley Guido y recepta, en la nueva normativa, la Ley Onganía). Los extranjeros serán admitidos en las siguientes categorías: residentes permanentes, temporarios y transitorios. Los dos primeros podrán ejercer actividad lucrativa (los temporarios sólo por el plazo autorizado) mientras que los transitorios no pueden. Los extranjeros de residencia precaria podrán hacerlo si están excepcionalmente habilitados mientras que los ilegales no podrán trabajar y nadie podrá darles trabajo o alojamiento oneroso. Los empleadores, dadores de trabajo y alojadores que infringieran las disposiciones legales, serán sancionados con multas severas. 
A partir de 1983, durante el gobierno de Alfonsín, se dicta una amnistía y, hacia 1985, se impone una política migratoria restrictiva considerando la grave situación económica. Solamente se aceptarán solicitudes de regularización migratoria de aquellos extranjeros que hubiesen ingresado al país con anterioridad al 8 de agosto de 1985. La excepción a esto se hará con los padres, hijos o cónyuges de argentinos o de residentes permanentes o temporarios, con migrantes con capital propio suficiente para desarrollar actividades productivas y otros. En 1987, se reglamenta la ley de migraciones dictada durante la última dictadura militar (Decreto 1434/87) (Novick 1, 1992); esta Ley $N^{\circ}$ 22.439, Ley General de Migraciones y de Fomento de la Inmigración, es un texto global y único que legisla sobre todos los aspectos del fenómeno migratorio.

Parte del presupuesto de la inmigración útil y beneficiosa al país, que debe fomentarse; encomienda la fijación de zonas prioritarias del país para promover el asentamiento de inmigrantes; establece como elementos activos de promoción de la inmigración, entre otros, los convenios de inmigración con otros países, programas crediticios de fomento, etc.; establece las categorías de residentes permanentes, residentes temporarios o residentes transitorios, dentro de las normas de admisión y permanencia de los extranjeros. Los residentes permanentes gozan de todos los derechos civiles de los nacionales y están sujetos a iguales obligaciones y deberes que éstos. Los residentes temporarios o transitorios podrán permanecer en el país, durante el plazo acordado por la autoridad de migración. Se crea la categoría de residencia precaria para aquellos que gestionan la regularización de su permanencia en el país, en los plazos que acuerde la autoridad competente. Se sienta el criterio básico de que los extranjeros con residencia permanente pueden desarrollar toda actividad lucrativa mientras que los que residen ilegalmente tienen prohibida la realización de tareas lucrativas. Esta ley es la actualmente vigente, y para su derogación e instauración de una nueva ley migratoria ya se están siguiendo los pasos pertinentes (Acosta Rivellini, 1985).

Finalmente, diremos que la Constitución Nacional de la República Argentina de 1994, incorpora la jerarquización constitucional de los Tratados Internacionales de Derechos Humanos y los recursos de amparo, siempre que no exista otro medio judicial más idóneo, contra todo acto u omisión de autoridades públicas o de particulares, que en 
forma actual o inminente lesione, restrinja, altere o amenace, con arbitrariedad o ilegalidad manifiesta, derechos y garantías reconocidos por esta Constitución, un tratado o una ley.

\section{A modo de conclusión}

Habiendo desarrollado un breve recorrido histórico acerca de la evolución de las políticas implementadas por los gobiernos nacionales, en Argentina, con relación a las personas migrantes, surgen algunas reflexiones a tener en cuenta.

La última ley sancionada respecto del tema, reconoce diferentes categorías legales de migrantes ¿podemos hablar, entonces, de la existencia de una política para la diversidad? La respuesta resulta definitivamente negativa. No solo no se observan políticas públicas, en tanto decisiones y acciones del gobierno, sino que no se observa en el espacio de "lo público"4 conductas de la población que respeten en todos los casos la diversidad, si es que coincidimos en que la política del reconocimiento es una política a favor de la diferencia como posibilidad de lograr la convivencia en una misma comunidad.

La tradición argentina del siglo XIX de fomentar la migración europea fue cambiando a lo largo del siglo XX. Es así que, y particularmente, durante la segunda mitad del siglo XX se incrementó el ingreso al país de personas provenientes de países limítrofes, que se incluyeron en condiciones de precariedad en el mercado de trabajo nacional. Esto generó que en ciertos rubros, tales como el de la construcción para los varones y el del servicio doméstico para las mujeres, se contratara a migrantes por remuneraciones menores en razón de su situación denominada de "ilegalidad". 5

Frente al cuadro descripto, no se observó una política pública tendiente a resolver el problema planteado y fue así que la situación se extendió en el tiempo. Dice Botana al respecto: “...hoy es evidente que la Argentina es menos igualitaria de lo que era. Tal vez tenga un régimen

\footnotetext{
${ }^{3}$ Lo público en tanto espacio donde se genera el bien común.

${ }^{4}$ Se habla de "ilegalidad" porque estas personas no figuraban como residentes en el país, aunque de hecho lo eran y por lo tanto debían retornar cada cierta cantidad de tiempo a su país de origen para acreditar su salida y volver a ingresar, o bien cruzar la frontera en forma irregular.
} 
político menos violento, tal vez ejerza más ampliamente las libertades. Pero la estructura de la sociedad es menos igualitaria" (Botana, 2002, p. 231).

Para finalizar diremos, siguiendo a Meza Rueda "En América Latina tenemos la tarea inaplazable de construir un Estado auténtico de derecho, fundado sobre la ley y el respeto a los derechos humanos" (Meza Rueda, 1999).

\section{REFERENCIAS}

Acosta Rivellini, L. G. (1985). El Marco jurídico de la inmigración en Argentina. Jornadas de Inmigración. Ministerio de Cultura y Educación. Buenos Aires.

Arango, A. (1985). Servicios sociales para la adaptación e integración de los migrantes. Jornadas de Inmigración. Ministerio de Cultura y Educación. Buenos Aires.

Botana, N. (2002). La república vacilante. Buenos Aires: Editorial Taurus.

Calderón, F. (1997). Diversidad cultural y ciudadanía. Leviatán, $\mathrm{N}^{\circ}$ 70, Madrid.

Glazer, N. (1983). Ethnic pluralism and public policy. Lexington, Mass.

Kymlicka, W. (1996). Ciudadanía multicultural. Barcelona: Paidós.

Kymlicka, W. y Norman, W. (1994). Return of the citizen: a survey of recent work on citizenship theory. Ethics, $N^{o} 104$. Chicago: The University of Chicago Press.

Meza Rueda, M. (1999). Elementos para una antropología de lo político. En Lo político en América Latina. Equipo Jesuita Latinoamericano de reflexión filosófica. Buenos Aires: Editorial Bonum.

Novick, S. (1992). Política y población/1. Argentina 1870-1989. Buenos Aires: Centro Editor de América Latina. 
Novick, S. (1992). Política y población/2. Argentina1870-1989. Buenos Aires: Centro Editor de América Latina.

Przeworski, A. y otros. (1998). Democracia sustentable. Buenos Aires: Paidós.

Rocha-Trindade, M. B. y otros. (1995) Sociologia das Migracoes. Lisboa: Universidad Aberta.

Rosoli, G. (1993). Migraciones internacionales, nuevas identidades étnicas y sociedades multiculturales. En Estudios Migratorios Latinoamericanos.

Tamir, Y. (1993). Liberal Nationalism. New Jersey: Princeton University Press.

Taylor, Ch. (1992). El multiculturalismo y la política del reconocimiento. México: Fondo de Cultura Económica.

Taylor, Ch. (1995). Identidad y reconocimiento. Conferencia en el Centro Cultural Internacional de Cerisy La Salle, Francia.

Tonon, G. (2001). Trabajo social: profesión y disciplina. Revista Saberes y Haceres, 3(3). (Universidad Autónoma del Sur, Chile).

Velleggia, S. (1997). Comunicaciones del Mercosur en la disyuntiva: ¿Globalización o integración subregional? En Recondo, G comp. Mercosur: la dimensión cultural de la integración. Buenos Aires: Ediciones Ciccus.

Vertovec, S. y Cohen, R. (1999). Migration, Diasporas and Transnationalism. Massachussets. Edward Elgard Publishing.

\section{Documentos}

Constitución Nacional de la República Argentina. 1853

Constitución nacional de la República Argentina. 1994

Convención Americana relativa a los Derechos Humanos. 1969 
Declaración Universal de los Derechos Humanos 1948.

Decreto 3.938/77. Poder Ejecutivo Nacional República Argentina

Ley Nacional 346. 1865

Ley Nacional 817. 1876.

Ley Nacional 4144. 1902

Ley Nacional 14.354.1954

Ley Nacional 22.439, Ley General de Migraciones y de Fomento de la Inmigración. 1987

Pacto Internacional sobre Derechos Civiles y Políticos.1966

Pacto Internacional sobre los Derechos económicos, sociales y culturales. 1966 
